И. И. Старкова, Е. В. Кондрашова, О. Ю. Фалилеева. Онлайн-экскурсия как одна из инновационных форм туристического обслуживания в условиях пандемии

Научная статья

УДК 379.857

DOI: $10.18101 / 2304-4446-2021-2-77-82$

\title{
ОНЛАЙН-ЭКСКУРСИЯ КАК ОДНА ИЗ ИННОВАЦИОННЫХ ФОРМ ТУРИСТИЧЕСКОГО ОБСЛУЖИВАНИЯ В УСЛОВИЯХ ПАНДЕМИИ
}

\section{(C) Старкова Ирина Ивановна}

кандидат социологических наук, доцент, Бурятский государственный университет имени Доржи Банзарова Россия, 670000, г. Улан-Удэ, ул. Смолина, 24а irina-ivanovna.8@mail.ru

\section{(C) Кондрашова Евгения Владимировна}

кандидат технических наук, доцент, Восточно-Сибирский государственный институт культуры Россия, 670031, г. Улан-Удэ, ул. Терешковой, 1 con.evg@mail.ru

\section{(C) Фалилеева Оксана Юрьевна}

кандидат технических наук, доцент, Восточно-Сибирский государственный институт культуры Россия, 670031, г. Улан-Удэ, ул. Терешковой, 1 faoxana@yandex.ru

Аннотация. В период неблагополучной эпидемиологической ситуации туристический бизнес оказался под угрозой. Пандемия коронавируса и введенные различными странами строгие ограничения ускорили трансформационные процессы туризма в мире и развитие новых технологий. Туристическая индустрия с приходом COVID-19 теряет миллиарды рублей и большое количество рабочих мест. Но вместе с тем на рынке появляются цифровые стартапы, новые инструменты для формирования индивидуальных туров и форматы международного сотрудничества. Виртуальные путешествия и онлайн-экскурсии в ближайшее время станут вспомогательным инструментом в выборе реальной поездки. Очевидно, что спрос на онлайн-экскурсии обусловила пандемия, но этот продукт будет существовать и дальше. При этом доступность смартфонов и мобильного интернета дает совершенно другой уровень возможностей для развития онлайн-экскурсий.

Ключевые слова: экскурсия, инновации, онлайн-экскурсия, туризм, пандемия

\section{Для цитирования}

Старкова И. И., Кондрашова Е. В., Фалилеева О. Ю. Онлайн-экскурсия как одна из инновационных форм туристического обслуживания в условиях пандемии // Вестник Бурятского государственного университета. Экономика и менеджмент. 2021. № 2. С. 77-82.

В настоящее время экскурсия как одна из форм туристического обслуживания становится популярной. Во-первых, экскурсия в целом и экскурсионное дело в частности с каждым годом все более доступны. Причин много: насыщенность рынка, что позволяет снижать стоимость экскурсии, чтобы отличаться от конку- 
рентов. Стандартизация технологического процесса составления экскурсий, что позволяет делать их более эффективными. Во-вторых, в связи с цифровизацией и автоматизацией проведения электронных экскурсий люди стали больше узнавать об окружающем их мире, посещать музеи, театры, города и другие районы показа. В-третьих, мощный «удар» по экскурсионному делу нанесла мировая пандемия COVID-19 (коронавирус), из-за которой вся мировая туристическая индустрия пострадала. Именно поэтому изучение роли и перспектив развития экскурсии в современном мире является актуальным.

Для оценки экскурсионного потенциала была выбрана территория Республики Бурятия. Отметим, что туристическая составляющая региона с каждым днем становится все более «насыщенной». В данной статье рассмотрено именно это направление в туризме, так как актуальность развития экскурсионного дела в Бурятии очень высока: республика отличается ярко выраженным национальным колоритом, огромным количеством исторических памятников, многообразием культур народов, мирно живущих в регионе.

В 2020 г. во всем мире была объявлена пандемия в связи с новым заболеванием COVID-19. Всеми странами мира были приняты определенные меры для предотвращения распространения болезни. Людям было запрещено покидать свои дома, не допускались массовые скопления людей в местах, где они хоть както могли контактировать друг с другом.

Туризм как одна из сфер мировой экономики особенно пострадал от введенных в большинстве стран ограничительных мер в целях предотвращения распространения коронавирусной инфекции. Именно по этой причине уже полгода все стараются найти выход из сложившейся ситуации, так как еще неизвестно, как долго продлятся ограничения, а также предотвратить повторную вспышку вируса.

В мире все время появляются новые технологии и возможности для роста и развития, туризм тоже входит в это число. Туристические предприятия смогли выйти на новый уровень. Так, музеи, театры, галереи и другие подобные учреждения начали проводить онлайн-экскурсии, концерты, лекции и вебинары. А с послаблением мер гиды-экскурсоводы также начали проводить онлайнэкскурсии, но уже по городам и популярным местам. Сегодня практически любой желающий может посетить знаменитые музеи, галереи и прогуляться по улицам знаменитых городов, не выходя из дома. Наблюдая за развитием данной тенденции, туристические предприятия стали активно продвигать свои продукты в интернете [1].

Следует отметить, что границы до сих пор закрыты и неизвестно, когда откроются. Многие страны, чей основной доход был связан со сферой туризма, сейчас несут колоссальные убытки. Чтобы оставаться востребованными в изменяющихся конкурентных условиях, предприятия туристической индустрии должны непрерывно развиваться. Особенно теперь, когда мировая экономика перестраивается и уходит в онлайн-пространство.

Инновации в экскурсионном деле позволяют успешно продвигать экскурсионные услуги на рынке и дают преимущество одних экскурсий над другими. 
И. И. Старкова, Е. В. Кондрашова, О. Ю. Фалилеева. Онлайн-экскурсия как одна из инновационных форм туристического обслуживания в условиях пандемии

Огромное значение отводится подготовке экскурсоводов, качественной разработке экскурсии, методике и технике проведения экскурсии ${ }^{1}$.

Предприятия, которые создают экскурсионный продукт, должны иметь оригинальную марку, учитывать спрос и предоставлять дифференцированное обслуживание для разных категорий потребителей. Новые экскурсии ведут к появлению новых экскурсионных объектов, разнообразию среди экскурсионных продуктов и различным формам подачи. Экскурсии прошли эволюцию от простых рассказов экскурсовода до современных 3D-экскурсий.

Разработка инновационных экскурсий является организованным и систематизированным процессом. Экскурсии с элементами инноваций должны создаваться с учетом природных, исторических и административных ресурсов региона, где имеется спрос на турпродукт, уровня инфраструктуры, состояния дорог, наличия квалифицированных специалистов, возможности инвестирования [2].

C приходом COVID-19 туристические и экскурсионные услуги стали невостребованными, так как в связи с эпидемиологической ситуацией людям нельзя собираться в группы и контактировать друг с другом. Однако из-за развития технологий и интернета можно проводить онлайн-экскурсии, чем и воспользовались экскурсоводы со всего мира. Теперь экскурсанты могут увидеть достопримечательности любого города, музея, театра или других учреждений, не выходя из дома.

Разработка онлайн-экскурсий является перспективным направлением для развития туризма в республике, так как уже существует множество онлайнэкскурсий по городам мира, все они, конечно, популярны. В соседнем городе Иркутске уже есть онлайн-экскурсии «Архитектурная онлайн-прогулка по Иркутску», «Три религии на берегу Байкала». Их проводит гид Ксения, и данные онлайн-прогулки достаточно популярны.

Виртуальная и онлайн-экскурсия - это разные понятия. Виртуальная экскурсия - это ролик, который может быть платным или находится в свободном доступе. Он записывается один раз и в последующем многократно повторяется, иногда бывает с уже устаревшей информацией, например, экспозиция музея или композиция предметов уже давно поменялись. А в записи мы смотрим на витрину со старой компоновкой артефактов.

Онлайн-экскурсия - это экскурсия в режиме реального времени. Она является уникальной, как и любая другая экскурсия. В онлайн-экскурсиях вы полноценный участник, где экскурсовод рассказывает специально для вас. По окончании экскурсии участники могут задать вопросы, уточнить непонятное и услышать пояснения. Преимуществом онлайн-экскурсий также является то, что она проходит в режиме «здесь и сейчас». Например, если это будет запись экскурсии, на дворе зима, а на мониторе вы видите прогулку по паркам города. Так, теряется ощущение полноты и удовлетворения от экскурсии.

Также онлайн-экскурсии бывают двух видов. Первая - экскурсовод проводит экскурсию из дома или студии. Гид ведет экскурсию, показывая ролики и фотографии. Второй вид подразумевает онлайн-экскурсию в прямом эфире, где экс-

${ }^{1}$ ГОСТ Р 54604-2011 «Туристские услуги. Экскурсионные услуги. Общие требования». URL: http://docs.cntd.ru/document/1200092284 (дата обращения: 24.01.2019). Текст: электронный. 
курсовод ходит по городу, показывает достопримечательности, архитектуру и другие детали. Чаще всего он работает в паре с оператором. Это почти как настоящая экскурсия, только без реального присутствия экскурсантов на месте. Экскурсант наблюдает за происходящим с экрана своего монитора, отвечает на вопросы гида и задает вопросы.

Конечно, экскурсии вживую с экскурсоводом не потеряют свою востребованность, однако сегодня, когда границы закрыты и сбор людей в группу запрещен, инновационные экскурсии стали актуальными. Они позволяют изучать и познавать мир дальше, несмотря на пандемию.

Также безусловным преимуществом онлайн-экскурсий является доступность, так как не все люди могут полететь в другую страну, посетить популярные туристические города и места.

Экскурсии в прямом эфире проходят на трех платформах. Первая — это YouTube. Однако бывает так, что не всем доступны ролики, за них необходимо заплатить.

Вторая платформа - это Zoom. Она бесплатная, ее можно с легкостью скачать на любое устройство из интернета. Но в бесплатной версии есть ограничения по времени, так что если экскурсовод проводит экскурсию больше часа, то разумнее заплатить за подписку.

Третья платформа - Skype, где есть следующие ограничения: не более 100 часов групповой видеосвязи в месяц, не более 10 часов в день и не более 4 часов на каждый групповой звонок.

Онлайн-экскурсии сегодня - это не новшество. Особенно во время пандемии их популярность выросла в разы. Люди стали больше интересоваться миром, и туристические предприятия подхватили волну заинтересованных туристов. Поэтому создание онлайн-экскурсии по г. Улан-Удэ будет своевременной и пользоваться спросом у туристов из других регионов.

Суть онлайн-экскурсий заключается в том, что экскурсовод вместе с оператором в реальном времени проводит экскурсию в прямом эфире. Для этого требуется лишь программа Zoom, она бесплатная и ее установка не требует каких-то особых навыков. В назначенное время экскурсант подключается к видеоконференции, используя идентификатор, который будет выслан на почту после оплаты экскурсии.

Приведем особенности организации онлайн-экскурсии:

1. Сезонность: круглогодичная.

2. Количество участников: до 100 человек, столько людей поддерживает Zoom.

3. В указанную дату, за 5 минут до начала, экскурсант должен перейти по ссылке. Ввести пароль, имя и войти в конференцию.

4. Во время онлайн-экскурсии:

- микрофон участников отключен, вы слышите только гида.

- не забудьте включить звук при входе и отключить камеру в случае необходимости.

4. B Zoom есть чат, но отвечать на все вопросы у экскурсовода не получится, поэтому он ответит на любые вопросы экскурсантов после экскурсии. 
И. И. Старкова, Е. В. Кондрашова, О. Ю. Фалилеева. Онлайн-экскурсия как одна из инновационных форм туристического обслуживания в условиях пандемии

5. Экскурсовод будет общаться с экскурсантами, ведь они могут отвечать на вопросы экскурсовода в чате. Это способствует более «живой» онлайнэкскурсии.

6. Методы рассказа в экскурсии:

- приемы характеристики.

- экскурсионной справки;

- заданий;

- новизны материала;

- дискуссионной ситуации;

- комментирования;

- вопросов-ответов;

- индукции и дедукции.

Методы показа в экскурсии:

- приемы зрительной реконструкции;

- предварительного осмотра;

- локализации событий;

- зрительного сравнения;

- зрительного монтажа;

- ассоциации;

- показа «портфеля экскурсовода»;

- движения.

Работа экскурсовода: во время онлайн-экскурсии он должен общаться, рассказывать и показывать объекты, учитывая особенности видеосъемки. Также у него должна быть хорошая аудиогарнитура, чтобы экскурсантам было хорошо слышно его.

Работа оператора: отвечает за показ объектов и экскурсовода в кадре. Он должен учитывать плавные переходы от экскурсовода на объект показа. А также во время рассказа экскурсовода демонстрировать объект синхронно.

Онлайн-экскурсии в Бурятии не очень развиты. Наибольшее распространение они получили во время карантина, когда люди сидели дома. Однако они не проводились с участием оператора и не демонстрировали достопримечательности в прямом эфире, как это делают в других крупных городах. В ближайшем городе Иркутске уже проводятся подобные онлайн-экскурсии, и впечатления у экскурсантов только положительные. Именно поэтому авторы считают, что разрабатываемые экскурсии будут пользоваться спросом, ведь любой человек, заинтересовавшийся городом и культурой Бурятии, сможет посетить экскурсию из любой точки мира.

Таким образом, в настоящее время экскурсии развиваются и не отстают от технологического развития общества. Они модернизируются, так как существует достаточное количество инноваций, которые можно применять в экскурсионной деятельности. Являясь одной из основных услуг, входящих в туристский продукт, экскурсия выполняет познавательные и воспитательные функции, а экскурсионная деятельность играет огромную роль в сфере образования населения.

\section{Литература}

1. Чернуха Д. С. Инновации и туризм: зарубежный опыт // Инновационные технологии управления социально-экономическим развитием регионов России: материалы 
VII Всероссийской научно-практической конференции с международным участием: в 2 частях. 2018. URL: http://elibrary.ru/item.asp?id=24049069 (дата обращения 24.01.2019). Текст: электронный.

2. Дашкова Е. В. К вопросу об инновациях в экскурсионном обслуживании // Индустрия туризма и сервиса: состояние, проблемы, эффективность, инновации: материалы II Международной научно-практической конференции. Н. Новгород, 2015. С. 11-16. Текст: непосредственный.

Статья поступила в редакцию 03.02.2021; одобрена после рецензирования 28.04.2021; принята к публикации 28.04.2021.

\section{ONLINE EXCURSION AS ONE OF THE INNOVATIVE FORMS OF TOURIST SERVICE AMIDST THE PANDEMIC}

Irina I. Starkova

Cand. Sci. (Sociol.), A/Prof.,

Dorzhi Banzarov Buryat State University

24a Smolina St., Ulan-Ude 670000, Russia

irina-ivanovna.8@mail.ru

Evgeniya $V$. Kondrashova

Cand. Sci. (Engineering), A/Prof.,

East-Siberian State Institute of Culture

1 Tereshkovoy St., Ulan-Ude 670031, Russia

con.evg@mail.ru

Oksana Yu. Falileyeva

Cand. Sci. (Engineering), A/Prof.,

East-Siberian State Institute of Culture

1 Tereshkovoy St., Ulan-Ude 670031, Russia

faoxana@yandex.ru

Abstract. During the period of adverse epidemiological situation, travel industry suffered damage. The coronavirus pandemic and heavy restrictions imposed by various countries have accelerated the transformation processes in tourism and the development of new technologies. Since the beginning of the COVID-19 pandemic, travel industry is losing billions of rubles and a large number of jobs. At the same time digital startups, new forms of independent tours and international cooperation are appearing on the market. Virtual trips and online excursions will soon become an auxiliary tool in choosing a real trip. Obviously, the pandemic has driven the demand for online excursions, but this product will continue to exist. The availability of smartphones and mobile Internet provides more opportunities for the development of online excursions.

Keywords: excursion, innovation, online excursion, tourism, pandemic

For citation

Starkova I. I., Kondrashova E. V., Falileyeva O. Yu. Online Excursion as One of the Innovative Forms of Tourist Service amidst the Pandemic. Bulletin of Buryat State University. Economy and Management. 2021; 2: 77-82 (In Russ.).

The article was submitted 03.02.2021; approved after reviewing 28.04.2021; accepted for publication 28.04.2021. 